Review

\title{
Ecology of Fungus Gnats (Bradysia spp.) in Greenhouse Production Systems Associated with Disease-Interactions and Alternative Management Strategies
}

\author{
Raymond A. Cloyd \\ Department of Entomology, Kansas State University, Manhattan, KS 66506, USA; \\ E-Mail: rcloyd@ksu.edu; Tel.: +1-785-532-4750; Fax: +1-785-532-6232 \\ Academic Editor: Andrew G. S. Cuthbertson \\ Received: 12 February 2015 / Accepted: 20 March 2015 / Published: 9 April 2015
}

\begin{abstract}
Fungus gnats (Bradysia spp.) are major insect pests of greenhouse-grown horticultural crops mainly due to the direct feeding damage caused by the larvae, and the ability of larvae to transmit certain soil-borne plant pathogens. Currently, insecticides and biological control agents are being used successively to deal with fungus gnat populations in greenhouse production systems. However, these strategies may only be effective as long as greenhouse producers also implement alternative management strategies such as cultural, physical, and sanitation. This includes elimination of algae, and plant and growing medium debris; placing physical barriers onto the growing medium surface; and using materials that repel fungus gnat adults. This article describes the disease-interactions associated with fungus gnats and foliar and soil-borne diseases, and the alternative management strategies that should be considered by greenhouse producers in order to alleviate problems with fungus gnats in greenhouse production systems.
\end{abstract}

Keywords: fungus gnats; pest management; plant protection; diseases; greenhouse; cultural control; sanitation; physical barriers; repellents

\section{Introduction}

Fungus gnats in the genus Bradysia spp. (Diptera: Sciaridae) are major insect pests of greenhouse production systems feeding on a wide-range of horticultural crops [1-3] with the commonly encountered species being Bradysia coprophila Comstock and B. impatiens Johannsen [4-6]. Fungus gnats, in general, are ubiquitous in greenhouses [7] but are primarily a problem under conditions of excessive moisture, 
which commonly occurs during propagation when cuttings and plugs are developing root systems [8,9]. The larval stage, which resides within the growing medium, feeds mainly on decaying plant material and fungi [10]. However, they will also feed on healthy plant roots and tunnel into stems of young cuttings and seedlings [4], and the crowns of mature plants [11]. Therefore, the larvae are primarily responsible for causing direct plant damage by feeding on the roots, thus interfering with the ability of plants to uptake water and nutrients, which results in wilting and stunted growth $[3,4,12,13]$. Fungus gnat adults are mainly a nuisance causing minimal direct plant damage [9].

A number of insecticides from different chemical classes and various biological control agents including a soil-dwelling predatory mite (Stratiolaelaps scimitus (Womersley)), a rove beetle (Dalotia coriaria Kraatz), and entomopathogenic nematode (Steinernema feltiae Filipjev) have been shown to be effective in suppressing or regulating fungus gnat populations [1,8,14-19]. However, these strategies may only be effective if alternative plant protection strategies are implemented simultaneously. Furthermore, sole reliance on insecticides may be an issue as there is the possibility of fungus gnats developing resistance to insecticides [20,21]. This article will discuss the disease-interactions associated with fungus gnats, and the alternative management strategies that should be considered so as to alleviate problems with fungus gnats in greenhouse production systems.

\section{Disease-Interactions}

Fungus gnat larvae not only cause direct damage during feeding but their feeding may predispose plants to attack from soil-borne plant pathogens by creating wounds, which allow entry of certain soil-borne fungi [12,22-24]. Furthermore, larvae are capable of directly transmitting certain fungal diseases including Pythium spp., Fusarium spp., and Verticillium spp., from diseased to non-infected plants [24-27]. It has been shown that fungus gnat larvae can transmit Thielaviopsis basicola Berk \& Broome, Fusarium oxysporum f. sp. radices-lycopersici Jarvis \& Shoemaker, Verticillium albo-atrum Reinke \& Berthold, and Fusarium avenaceum (Fr:Fr) [24,27-30]. It has also been reported that the oospores of certain Pythium spp. may survive passage through the digestive tract of $B$. impatiens larvae, which might be intact/viable after being excreted [24]. Furthermore, larvae of the fungus gnat, $B$. impatiens have been shown to ingest the propagules of Pythium aphanidermatum (Edson) and macroconidia of $F$. avenaceum that can then be introduced into young healthy plants during the feeding process $[13,30]$. Under laboratory conditions, fungus gnat larvae are capable of transmitting Pythium spp.; however, the extent of larval transmission may be less of a factor under greenhouse conditions, and may vary depending on the specific Pythium species [31]. In addition, it has been suggested, based on laboratory experiments, that fungus gnat larval feeding may decrease geranium seedling (Pelargonium $\times$ hortorum L.) susceptibility to Pythium infection or at least there is no enhancement in infection [32]. However, this may not represent what would occur under greenhouse conditions.

Fungus gnat adults are capable of carrying, on their bodies, the aerial conidia of certain foliar and soil-borne plant pathogenic fungi that produce aerial dispersal stages such as Botrytis cinerea Pers.:Fr., F. avenaceum, F. acuminatum (Ellis \& Everhart), T. basicola, V. dahliae Kleb., and V. albo-atrum, which can then be transmitted to healthy plants [25,27-29,33]. Adult fungus gnats may not be able to vector Pythium spp., because any sexual and/or asexual reproductive structures are produced belowground (there are no aerial dispersal stages), which are not accessible to fungus gnat adults for acquisition because adults live aboveground [34,35]. 
Although adults do not fly very well and tend to reside near the growing medium, they may still be able to disperse spores of foliar plant pathogens in localized areas of the greenhouse [33]. The potential for both life stages of fungus gnats to transmit diseases means that the tolerance level for the presence of this pest may be very low, which is similar to other insect pests that vector diseases such as the western flower thrips, Frankliniella occidentalis Pergande [36]. Moreover, this means that intensive plant protection practices need to be implemented including alternative management strategies.

\section{Alternative Management Strategies}

Moisture management and sanitation are important in reducing problems with fungus gnats in greenhouse production systems. The use of well-drained growing media and not over-watering plants may avoid issues with soil-borne plant pathogenic fungi, thus diminishing the possibility of disease transmission by the larvae and adult. The accumulation of water and presence of algae may lead to abundant populations of fungus gnats and thus damage to greenhouse-grown crops [37]. Therefore, the installation of cement flooring may eliminate problems with algae, and consequently fungus gnats. However, this may not be economically feasible. A more cost-effective strategy may be to use landscape or weed fabric barriers, which are geotextile, non-biodegradable materials that when installed underneath benches may reduce algae growth and thus mitigate problems with fungus gnats [11]. It is also important to remove plant material and growing medium debris immediately from the greenhouse or place into containers, located within greenhouses, with tight-sealing lids, as fungus gnat adults may emerge from disposed growing medium and migrate onto the main crop [38].

An alternative strategy that should be considered in order to alleviate problems with fungus gnats is the use of physical barriers. Physical barriers are designed to alter the environment in order to make it inaccessible to insect pests [39]. Physical barriers do not reduce insect pest populations immediately, which is typical of most insecticides [40]; however, placing a physical barrier on the surface of the growing medium may inhibit fungus gnat adult emergence and also possibly reduce female egg-laying or egg survival [41].

It has been hypothesized that physical barriers such as sand or diatomaceous earth placed on the surface of the growing medium would negatively impact fungus gnat adults when they emerge and/or prevent females from laying eggs [42]. Diatomaceous earth is composed of siliceous skeletonized diatoms [43], which remove the insect cuticle waxes, absorb oils and waxes on the outer cuticle, or disrupt the integrity of the insect cuticle resulting in extensive loss of water from the insect body [44]. However, it has been shown that placing diatomaceous earth or sand on the growing medium surface did not have any effect on fungus gnat adult emergence or inhibit females from laying eggs because these physical barriers contain small openings that allow larvae to pupate, and adult females to lay eggs $[41,45]$.

Growstones $^{\mathrm{TM}}$ (Growstone, Inc., Albuquerque, NM, USA) aggregates, which are processed from 100\% recycled glass and are used as a substrate in hydroponic systems [46] have been used as physical barriers and shown to reduce fungus gnat adult emergence over time and may also reduce egg-laying or egg survivability although this depends on the thickness of the Growstones ${ }^{\mathrm{TM}}$ layer [47]. It is important to note, that a physical barrier is not a stand-alone practice and therefore must be used as part of a holistic plant protection strategy [39]. This strategy may be more effective with plants growing in large containers whereas physical barriers may not be feasible under propagation due to the excessively moist conditions and small size of the containers. 
Another potential alternative strategy to minimize plant damage due to fungus gnats is by repelling fungus gnat adults away from the growing medium thus reducing egg-laying. Repellent compounds have been used against other insects such as mosquitoes [48,49]. It was discovered, under laboratory conditions, that Bounce ${ }^{\circledR}$ original brand fabric softener dryer sheets (Outdoor Fresh Scent; Procter and Gamble, Cincinnati, $\mathrm{OH}$ ) actually repel fungus gnat adults [50]. The dryer sheets contain several volatile constituents including linalool (3,7-dimethyl-1,6-octadien-3-ol), a colorless monoterpene alcohol that is present naturally in plants such as lavender (Lavandula angustifolia Mill.), marjoram (Origanum vulgare L.), and basil (Ocimum basilicum L.) [51-53]. In fact, greenhouse producers are actually inserting dryer sheets into the growing medium to repel fungus gnat adults [11]. However, one problem with this strategy is that fungus gnat adults are not killed directly and may migrate into other areas of the greenhouse. Therefore, dryer sheets must be placed throughout the greenhouse in order to protect plants from fungus gnat adults.

Finally, the use of jasmonate has been investigated to determine if stimulating wound signaling pathways may protect plants against fungus gnat larvae. This is based on the premise that signaling pathways, when activated by insects with chewing mouthparts, may allow plants to defend themselves by producing secondary metabolites [54]. However, it was found that applications of methyl jasmonate to Arabidopsis thaliana plants resulted in no mortality or reduced feeding activity of fungus gnat larvae [55].

\section{Conclusions}

It is important to understand that fungus gnats, both larvae and adults, may transmit certain soil-borne plant pathogens (e.g., fungi) to greenhouse-grown horticultural crops, either directly or indirectly thus potentially resulting in an economic loss. Although insecticides and biological control agents are effective against fungus gnat larval populations, alternative plant protection strategies should also be implemented. This includes cultural, sanitation, physical barriers, and use of repellent materials. These strategies may contribute to enhancing the efficacy of insecticides and biological control agents in suppressing or regulating fungus gnat populations in greenhouse production systems.

\section{Acknowledgments}

The author wishes to acknowledge Amy L. Raudenbush, Amy Dickinson, Erik R. Echegarary, Karen A. Marley, and Richard A. Larson from the University of Illinois (Champaign, IL, USA) and Kansas State University (Manhattan, KS, USA) for all of their collective assistance in conducting research with fungus gnats. The author also wants to thank Mary Beth Kirkham, Professor from the Department of Agronomy at Kansas State University for reviewing an initial draft of the manuscript.

\section{Conflicts of Interest}

The author declares no conflict of interest.

\section{References}

1. Hamlen, R.A.; Mead, F.W. Fungus gnat larval control in greenhouse plant production. J. Econ. Entomol. 1979, 72, 269-271. 
2. Jagdale, G.B.; Casey, M.L.; Grewal, P.S.; Lindquist, R.K. Application rate and timing, potting medium, and host plant effects on the efficacy of Steinernema feltiae against the fungus gnat, Bradysia coprophila, in floriculture. Biol. Control 2004, 29, 296-305.

3. Vaughan, M.M.; Tholl, D.; Tokuhisa, J.G. An aeroponic culture system for the study of root herbivory on Arabidopsis thaliana. Plant Methods 2011, 7, 5-14.

4. Wilkinson, J.D.; Daugherty, D.M. The biology and immature stages of Bradysia impatiens (Diptera: Sciaridae). Ann. Entomol. Soc. Am. 1970, 63, 656-660.

5. Alberts, S.A.; Kennedy, M.K.; Carde, R.T. Pheromone-mediated anemotactic flight and mating behavior of the sciarid fly Bradysia impatiens. Environ. Entomol. 1981, 10, 10-15.

6. Lindquist, R.K.; Faber, W.R.; Casey, M.L. Effect of various soilless root media and insecticides on fungus gnats. HortScience 1985, 20, 358-360.

7. Harris, M.A.; Gardner, W.A.; Oetting, R.D. A review of the scientific literature on fungus gnats (Diptera: Sciaridae) in the genus Bradysia. J. Entomol. Sci. 1996, 31, 252-271.

8. Chambers, R.J.; Wright, E.M.; Lind, R.J. Biological control of glasshouse sciarid flies (Bradysia spp.) with the predatory mite, Hypoaspis miles, on cyclamen and poinsettia. Biocontrol Sci. Technol. 1993, 3, 285-293.

9. Cloyd, R.A. Fungus gnat and shore fly management strategies: Panel discussion. In Proceedings of the 16th Conferences Insect and Disease Management Ornamentals, Society of American Florists, Alexandria, VA, USA, 19-21 February 2000; King, A.I., Greene, I.D., Eds.; Society of American Florists: Alexandria, VA, USA, 2000; pp. 57-59.

10. Kennedy, M.K. Survival and development of Bradysia impatiens (Diptera: Sciaridae) on fungal and non-fungal food sources. Ann. Entomol. Soc. Am. 1974, 67, 745-749.

11. Cloyd, R.A. Horticultural Entomology/Plant Protection, Department of Entomology, Kansas State University, Manhattan, KS, USA. Personal observation, 2014.

12. Fawzi, T.H.; Kelly. W.C. Cavity spot of carrots caused by feeding of fungus gnat larvae. J. Am. Soc. Hort. Sci. 1982, 107, 1177-1181.

13. Jarvis, W.R.; Shipp, J.L.; Gardiner, R.B. Transmission of Pythium aphanidermatum to greenhouse cucumber by the fungus gnat Bradysia impatiens (Diptera: Sciaridae). Ann. Appl. Biol. 1993, 122, 23-29.

14. Harris, M.A.; Oetting, R.D.; Gardner, W.A. Use of entomopathogenic nematodes and a new monitoring technique for control of fungus gnats, Bradysia coprophila (Diptera: Sciaridae), in floriculture. Biol. Control 1995, 5, 412-418.

15. Gouge, D.H.; Hague, N.G.M. Glasshouse control of fungus gnats, Bradysia paupera, on fuchsias by Steinernema feltiae. Fund. Appl. Nematol. 1995, 18, 77-80.

16. Ludwig, S.W.; Oetting, R.D. Evaluation of medium treatments from management of Frankliniella occidentalis (Thripidae: Thysanoptera) and Bradysia coprophila (Diptera: Sciaridae). Pest Manag. Sci. 2001, 57, 1114-1118.

17. Carney, V.A.; Diamond, J.C.; Murphy, G.D.; Marshall, D. The potential of Atheta coriaria Kraatz (Coleoptera: Staphylinidae), as a biological control agent for use in greenhouse crops. IOBC/WPRS Bull. 2002, 25, 37-40. 
18. Cloyd, R.A.; Dickinson, A. Effect of Bacillus thuringiensis subsp. israelensis and neonicotinoid insecticides on the fungus gnat Bradysia sp. nr. coprophila (Lintner) (Diptera: Sciaridae). Pest Manag. Sci. 2006, 62, 171-177.

19. Cloyd, R.A.; Chiasson, H. Activity of an essential oil derived from Chenopodium ambrosioides on greenhouse insect pests. J. Econ. Entomol. 2007, 100, 459-466.

20. Brewer, K.K.; Keil, C.B. A mixed function oxidase factor contributing to permethrin and dichlorvos resistance in Lycoriella mali (Fitch) (Diptera: Sciaridae). Pestic. Sci. 1989, 26, 29-39.

21. Bartlett, G.R.; Keil, C.B.O. Identification and characterization of a permethrin resistance mechanism in populations of the fungus gnat Lycoriella mali (Fitch) (Diptera: Sciaridae). Pestic. Biochem. Physiol. 1997, 58, 173-181.

22. Leath, K.T.; Newton, R.C. Interaction of a fungus gnat, Bradysia sp. with Fusarium spp. on alfalfa and red clover. Phytopathology 1969, 59, 257-258.

23. Graham, C.L.; McNeill, M.J. Soybean crown and root damage by Bradysia coprophila. J. Econ. Entomol. 1972, 65, 597-599.

24. Gardiner, R.B.; Jarvis, W.R.; Shipp, J.L. Ingestion of Pythium spp. by larvae of fungus gnat Bradysia impatiens (Diptera: Sciaridae). Ann. Appl. Biol. 1990, 116, 205-212.

25. Kalb, D.W.; Millar, R.L. Dispersal of Verticillium albo atrum by the fungus gnat (Bradysia impatiens). Plant Dis. 1986, 70, 752-753.

26. Favrin, R.J.; Rahe, J.E.; Mauza, B. Pythium spp. associated with crown rot and cucumbers in British Columbia greenhouses. Plant Dis. 1988, 72, 683-687.

27. Gillespie, D.R.; Menzies, J.G. Fungus gnats vector Fusarium oxysporum f. sp. Radicis-lycopersici. Ann. Appl. Biol. 1993, 123, 539-544.

28. Harris, M.A. Dissemination of the Phytopathogen Thielaviopsis basicola by the Fungus gnat Bradysia coprophila and Biological Control of these Pests by Fusarium proliferatum and steinernematid Nematodes. Ph.D. Thesis, University of Georgia, Athens, GA, USA, 1995.

29. James, R.L.; Dumroese, R.K.; Wenny, D.L. Botrytis cinerea carried by adult fungus gnats (Diptera: Sciaridae) in container nurseries. Tree Planters Notes 1995, 46, 48-53.

30. El-Hamalawi, Z.A.; Stangellini, M.E. Disease development on lisianthus following aerial transmission of Fusarium avenaceum by adult shore flies, fungus gnats, and moth flies. Plant Dis. 2005, 89, 619-623.

31. Braun, S.E.; Sanderson, J.P.; Wraight, S.P. Larval Bradysia impatiens (Diptera: Sciaridae) potential for vectoring Pythium root rot pathogens. Phytopathology 2012, 102, 283-289.

32. Braun, S.E.; Sanderson, J.P.; Nelson, E.B.; Daughtrey, M.L.; Wraight, S.P. Fungus gnat feeding and mechanical wounding inhibit Pythium aphanidermatum infection of geranium seedlings. Phytopathology 2009, 99, 1421-1428.

33. El-Hamalawi, Z.A. Acquisition, retention and dispersal of soilborn plant pathogenic fungi by fungus gnats and moth flies. Ann. Appl. Biol. 2008, 153, 195-203.

34. Hyder, N.; Coffey, M.D.; Stanghellini, M.E. Viability of oomycete propagules following ingestion and excretion by fungus gnats, shore flies, and snails. Plant Dis. 2009, 93, 720-726.

35. Braun, S.E.; Castrillo, L.A.; Sanderson, J.P.; Daughtrey, M.L.; Wraight, S.P. Transstadial transmission of Pythium in Bradysia impatiens and lack of adult vectoring capacity. Phytopathology 2010, 100, 1307-1314. 
36. Parrella, M.P.; Jones, V.P. Development of integrated pest management strategies in floricultural crops. Bull. Entomol. Soc. Am. 1987, 33, 28-34.

37. Keates, S.E.; Sturrock, R.N.; Sutherland, J.R. Populations of adult fungus gnats and shore flies in British Columbia container nurseries as related to nursery environment, and incidence of fungi on the insects. New For. 1989, 3, 1-9.

38. Hogendorp, B.K.; Cloyd, R.A. Insect management in floriculture: How important is sanitation is avoiding insect problems? HortTechnology 2006, 16, 633-636.

39. Banks, H.J. Physical control of insects-Recent developments. J. Aust. Entomol. Soc. 1976, 15, 89-100.

40. Boiteau, G. Physical Barriers for the Control of Insect Pests. In Encyclopedia of Pest Management; Pimentel, D., Ed.; Marcel Dekker, Inc.: New York, NY, USA, 2002; pp. 616-618.

41. Cloyd, R.A.; Dickinson, A.; Kemp, K.E. Effect of diatomaceous earth and Trichoderma harzianum T-22 (Rifai Strain KRL-AG2) on the fungus gnat Bradysia sp. nr. coprophila (Diptera: Sciaridae). J. Econ. Entomol. 2007, 100, 1353-1359.

42. Quarles, W. Diatomaceous earth for pest control. IPM Practitioner 1992, 14, 1-11.

43. Ebeling, W. Sorptive dusts for pest control. Ann. Rev. Entomol. 1971, 16, 123-158.

44. Korunic, Z. Diatomaceous earths, a group of natural insecticides. J. Stored Prod. Res. 1998, 34, 87-97.

45. Cloyd, R.A.; Dickinson, A. Effects of growing media containing diatomaceous earth on the fungus gnat Bradysia sp. nr. coprophila (Lintner) (Diptera: Sciaridae). HortScience 2005, 40, 1806-1809.

46. Evans, M.R. Physical properties of and plant growth in peat-based root substrates containing glass-based aggregate, perlite, and parboiled fresh rice hulls. HortTechnology 2011, 21, 30-34.

47. Raudenbush, A.L.; Cloyd, R.A.; Echegaray, E.R. Effect of physical barrier on adult emergence and egg survival associated with the fungus gnat, Bradysia sp. nr. coprophila (Diptera: Sciaridae), under laboratory conditions. HortScience 2014, 49, 905-910.

48. Rutledge, L.C.; Collister, D.M.; Meixsell, V.E.; Eisenberg, G.H.G. Comparative sensitivity of representative mosquitoes (Diptera: Culicidae) to repellents. J. Med. Entomol. 1983, 20, 506-510.

49. Fradin, M.S.; Day. J.F. Comparative efficacy of insect repellents against mosquito bites. N. Engl. J. Med. 2002, 347, 13-18.

50. Cloyd, R.A.; Marley, K.A.; Larson, R.A.; Arieli, B. Bounce ${ }^{\circledR}$ fabric softener dryer sheets repel fungus gnat, Bradysia sp. nr. coprophila (Diptera: Sciaridae), adults. HortScience 2010, 45, 1830-1833.

51. Mansour, F.; Ravid, U.; Putievsky, E. Studies of the effects of essential oils isolated from 14 species of Labiatae on the carmine spider mite, Tetranychus cinnabarinus. Phytoparasitica 1986, 14, 137-142.

52. Morales, M.R.; Simon, J.E.; Charles, D.J. Comparison of essential oil content and composition between field and greenhouse grown genotypes of methyl cinnamate basil (Ocimum basilicum L.). J. Herbs. Spices Med. Plants 1993, 1, 25-30.

53. Narusuye, K.; Kawai, F.; Matsuzaki, K.; Miyachi, E. Linalool suppresses voltage-gated currents in sensory neurons and cerebellar purkinije cells. J. Neural Transm. 2005, 112, 193-203.

54. Ryan, C.A. Protease inhibitors in plants: Genes for improving defenses against insects and pathogens. Annu. Rev. Phytopathol. 1990, 28, 425-429. 
55. McConn, M.; Creelman, R.A.; Bell, E.; Mullet, J.E.; Browse, J. Jasmonate is essential for insect defense in Arabidopsis. Proc. Natl. Acad. Sci. USA 1997, 94, 5473-5477.

(C) 2015 by the authors; licensee MDPI, Basel, Switzerland. This article is an open access article distributed under the terms and conditions of the Creative Commons Attribution license (http://creativecommons.org/licenses/by/4.0/). 